\title{
Study on Expertise Development Process Based on Arête
}

\author{
Young Koung Moon, Eun Jung Kim, and Yeong-Mahn You
}

\begin{abstract}
The purpose of this study is to clarify the concept of arête implying one's intellectual and moral excellence, so as to discusses that the genuine concept of expertise development should be reflected in mirror of the distinction of competence, motive, and reason, and that it may illuminate its right attributes as a process. This study presents expertise development process from how expertise can be defined, what are components of expertise, how expertise develops in the process of interacting components, and what the mechanism enabling and promoting the interactions.
\end{abstract}

Index Terms -Arête, expertise, expertise development, explanation by competence, motive, and reason.

\section{INTRODUCTION}

As gaining expertise is becoming more and more essential in the knowledge-based society to survive in a national, organizational, and personal dimension, expertise development is coming to an important goal of human resources development. Competitiveness of organizations like companies is maintained by the core competencies making it possible to create continually differentiated products and services, and the source of the core competencies comes from the organizational unique expertise competencies distinguished from other organizations. After all, the experts' knowledge creating activities at a high intellectual level have been the motive power of social development and the experts have been a principal force in leading the advance of knowledge-based industries.

Numerous studies have been studied to examine expertise development, and those studies may have important implications for human resource development. First, studies on expertise development are necessary to be delivered in forms of its contents and types according to newly suggested components of expertise like experience, problem-solving skills, creativity, intuition, values, attitudes and others as well as knowledge or skill. Second, experience has been emerged as a key element of expertise [1]-[3]. For this reason, it needs to range over to understanding personal experience and its application as a major issue of expertise development [4], [5]. Third, the fact that expert goes through a series of growing processes is full of suggestions in developing organization's human resources development system [6]-[10].

On the other hand, existing studies on expertise have a few limitations from the point of view of human resource development. First, the studies had been focused on characters and components of expertise rather than the

Manuscript received November 25, 2012; revised January 13, 2013.

The authors are with Hanynag University, Seoul, 133791 Korea (e-mail: 0726moonr@naver.com, euni@hanyang.ac.kr,010000@ hanyang.ac.kr). process of how an individual does learn and develop expertise. It is important to study upon the components of expertise, but it also needs to be studied on knowledge system about how expertise develops and can be developed to foster a variety of professionals in various fields. Today, notion of the expert have been enlarged from intellectuals or professionals to practical-minded persons who have shown distinctive competence in a variety of situations [11]. Accordingly notion of expertise also have been understood as the ability to improve tacit knowledge through a wealth experience and practice rather than theoretical knowledge or technology itself belongs to specific domain [12], [13]. Second, environmental or social factors surrounding individuals are nearly excluded according to expertise understood in limited definition only as meaning of personal dimension. Individuals exist in the middle of continual interactions with its surroundings and that is the experience [14]. Numerous studies explaining experience as one of the main components of expertise indirectly, however, demonstrate that expertise is determined from the situation or context individuals belong to and its obtaining and development carry an important meaning [15], [16]. Therefore to fully comprehend expertise, it deserves special consideration not only upon individuals themselves but also environmental and social aspects. Third, there is no specific and agreed expertise development. Considerable studies tried to determine expertise development process [17]-[20]. But most studies can't explain how the expertise reaches to a specific level or stage by multiple mechanisms. Accordingly we have to develop specific and realistic model for how expertise develops.

This study will find a new way to overcome limitations of earlier studies on expertise. We will present expertise development process about how expertise can be defined, what are components of expertise, how expertise develops in the process of interacting components, and what the mechanism enabling and promoting the interactions are.

\section{CONCEPT OF THE EXPERTISE}

Expertise has been understood high-level technical skills and a lot of knowledge possessed by individuals on specific field, and also mentioned as characteristics, skill, and knowledge distinguishing between the expert and the inexpert [21]. Recently the notion of the expert or the expertise is starting to be re-recognized among researchers and it still could not reach an agreement in theories. The earlier studies have been confined expert performance to particular area. Expertise was recognized as individual ability connecting with specific field [22]. As knowledge has been created and decayed constantly and the science of information develops, expertise is no longer limited ability in 
specific field. In other words, it is required for expert to organize and systemize well from information and knowledge of each different fields rather than to know much about a specific field [23]. So definition of expertise is needed to reflect social changes in the world. Expertise can be interpreted performance component and process as well as performance outcome in human resource development site. Performance means outcome and product in addition to behavior or process in human resource development. Consequently definition of expertise needs to be explained in terms of its outcome and practice.

Swanson formed some hypotheses before discuss definition of expertise. First, expertise is not destination but a journey. Second, people have any level of expertise. Third, individual expertise is important and original interests in human resource development. Accordingly, notion of expertise needs to limit and inquire though difference of technology, knowledge, endeavors, learning, outcome, training, education similar in expertise. We have to consider expertise though definition of process or precondition avoiding from only taking count in the outcome of expertise. Expertise as all phenomena takes place inside the body in a human and a holistic approach by a human of external and internal interaction means 'spirit' [24].

\section{COMPONENT OF EXPERTISE}

The components of the expertise are identified as comparative study between the novice and the expert or the expert and the non-expert in each field. According to each the study suggesting different components of expertise, the debates had been around for many decades. The components of the expertise generally presented are the knowledge, Experience, skills and so on.

It is very recently claimed that it does little to truly explain what is the expertise only with the main components such as knowledge, experience and skills [25]-[28]. It is necessary to give explanation about environmental characteristics that influence the one's expertise such as tangible and intangible resources, the unique qualities of its own filed, and the interactions among human, material, and socio-cultural environment surrounding the person. It is also important to identify the characteristics of the dynamic changes and interactions with the environment among the components. The system thinking taking the individual for the part of the environment is required for this [29], [30].

The components of the expertise have been brought to light as the specific actions of the expert, not just in the independent state of each component but in the interactions among them. The expertise takes forms in mutual complex activities such as gaining knowledge, reorganizing the information, and the efforts of developmental problem solving in the process of learning caused by ceaseless interactions among the components [31]. It is able to understand that developing expertise means the changes of the components in qualitatively different level of characteristics. The expertise manifest itself in a series of continual process which consists of an intuitive judgment and decision making about unforeseen occurrences, knowing-in-action which is the knowledge accumulated in the process, reflection-in-action and reflection-on-action through it as Schon told [5].

Ko [32] describes 'practical concept' as the concept leading the one involved in the practice into understanding why the practice is needed and how it can be realized and participating in it actually. The practical concept has two meanings, 'the standard of meaning for understanding what the practice is' and 'the force leading the practice'. According to it, the expertise in practice means that the expert should understand his own practice fully and participate in it with enthusiasm. The development of the expertise should be also an autonomous development in the ways exposing clearly the meaning of the practical concept in the practice and creating favorable conditions for exercising one's utmost faculties. There are three different modes which are competence, motive and reason to understand expertise in practical concept. They are based on Kant's categories about the practical concept. It is divided into moral-practical concept based on liberty and descriptive-practical concept based on 'nature' [33]. The moral-practical concept is reinterpreted in 'reason', and the descriptive-practical concept in 'motive' and 'competence'.

First, Competence focuses on the magnitude of force one exercise and ability to lead actions in a various magnitude of force. It only explains how one can achieve aims related to the action, not what the aim of the action is worth or how much one favors it. Peters [34] intended to explicate human behaviors not in the law of causality but in the rules or custom the individual in the society follow. Second, Motive is the aim one wants to accomplish and the intention to realize in his own view. It is a certain personal reason in a certain context and based on a personal level taking a serious view of individual freedom and independence. Third, Reason is the principle or the regulation which a doer follows consciously and deliberately keeps asking questions to himself about what is the principle or the regulation of his practice. It reflects the inner state of the doer derived from his personal mind. The criterion of the reason that he keeps considering on its appropriateness is not in his personal criterion, but it follows the criterion of the given society. It has strong connotations of societal and environmental meaning.

Those three components are brought to light in the form of 'mind as a whole' unified competence, motive, and reason altogether, as it were, Spirit, rather than in the form of classified into three independent categories. It may be visualized as Fig. 1. Those three components do not make a clear division, but exercise a great influence upon each other and expands continues to push the boundaries united as to make a perfect circle. It illustrates its dynamic and consistent growing attributes of each component.

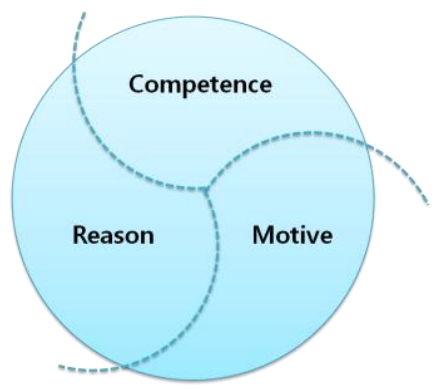

Fig. 1. Three components of the expertise 


\section{DEVElopment OF THE EXPERTISE}

It is recognized the expertise gradually grows up and is changes through the phased developmental process and each phase has unique characteristics [7], [25], [35]. Dreyfus \& Dreyfus [35] suggest 'five stage theory' that expertise development can be realized by going through qualitatively different cognition stages about the problem, whereas Feldman [9] proposes 'nonuniversal theory' development occurs in domain-specific stages from novice to master. Alexander [25], also, considers fostering the knowledge, strategies, and motivations to increase expertise focusing on the interactions among essential factors, and its attention to the transitions and trajectories across varying levels of competence.

The above theories, however, suggest the expertise development in linear process, so it is difficult to explain dynamics of developing expertise, differences between domains, and interactions. This paper sheds light on that expertise is not the ultimate state of goal to attain, but the nonlinear process state of formation arising from experiences, learning, specific context, and the given situations and formatting [31]. The domains and features of expertise are subject to extreme changes, because they belong to the rapidly changing world. The developmental process in expertise must be viewed as the complex process comprised of stagnation, retrogression, and growth. Rise in expertise should be understood in terms of the pursuing process.

Conceptualizations of expertise are supposed to be approached from a viewpoint of Bertalanffy's [36] general system theory. He said every living organism is essentially an open system. It maintains itself in a continuous inflow and outflow, a building up and breaking down of components, never being, so long as it is alive, in a state of chemical and thermodynamic equilibrium but maintained in a so-called steady state which is distinct from the latter. In system theory, people can comprehend the meaning of expertise with the features of conjunction in individual components after describing the conditions of inter-connected networks. Different from the closed system distinctive in homeostasis, the open system does not inevitably reach the equilibrium among components rather than reach a stationary state of homeostasis and soon can be changed or disintegrated. Internal systems' operations form self-organization process and turn themselves into an organic system in the process of adaptation and change of an open system.

Developing expertise in system theory can be told as the formation of a self-organization process in three different systems in terms of motive, competence, and reason. Motive is a self system because it reflects learners' psychological state and freedom and originates from the doer himself. He is the one who keeps considering whether to take or not whatever the stimuli are. Competence is a practice system making it possible to practice and learn and playing a major role in functioning. It leads actions in developing expertise with controlling the scope of abilities one can use. The above two system are necessary to guide to the right directivity. That is reason, namely meta system judging the value of the practice by taking some time for asking oneself questions about the justification of it. It may be shown as Fig. 2 below.

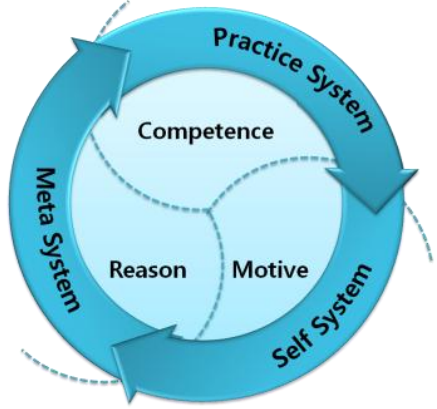

Fig. 2. Three components and systems of the expertise.

Aarête in the Classical Greek world is most interpreted to 'virture'. But, many scholars have been claimed that it does not fully explain its proper meaning [37], [38]. According to Jaeger, 'the root of arête is the same as that of aristos, which shows superlative ability and superiority, and aristos was constantly used in the plural to denote the nobility.' In addition, Jaeger also points out that in Homer's time, 'the adjective agathos, which corresponds to the noun arête though it derives from a different root, came to imply the combination of nobility and valour in war. It meant sometimes "noble" and sometimes "brave" or "capable," but it seldom meant "good" in the latter sense, any more than arête meant "moral virtue." Plato's analysis in the Republic, where he aligns each virtue as the excellence of that activity natural and appropriate to defining aspects of the individual as well as the state. He described arête as the standard of excellence, implicit in any act: the aspiration for quality will drive a craftsman to improve, to get better rather than get by [39].

Expertise is the fully realized state of functions in the one including body and mind, that is to say showing one's talent to the full. The person closed to arête is able to have time to spare for reflecting his own practice in action. The composure of mind leads to the experience of the states maximized by the power of reflection-in-action. Arête means ideal type of being and becoming in the ceaseless process at the same time. There are no such conceptualizations of the completed expertise, because they only exist in ideal type and never can be realized.

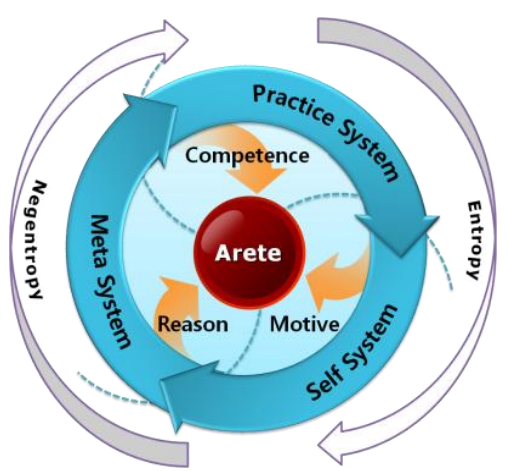

Fig. 3. Dynamics of expertise development.

When 'mind as a whole' self system, practice system, and meta system converged gives a whole new meaning to individual life and makes a constant effort, arête becomes driving force of expertise. Therefore, to the person with craftsmanship pursuing arête, life itself becomes self system and meta system in one. In this case practice system becomes 
a mental ability unconsciously leading the one's motive and reason in one with achieving the goal. With active interactions among them, a person stands between the process of entropy and negentropy. The negentropy of a living system is the entropy that it exports to keep its own entropy low; it lies at the intersection of entropy and life. The concept and phrase 'negative entropy' were shorten the phrase to negentropy by Léon Brillouin to express it in a more "positive" way: a living system imports negentropy and stores it. It may be shown as Fig. 3 below.

\section{PROCESS OF EXPERTISE DEVELOPMENT}

Expertise development in the true sense of the term is can be told as a self-creating learning process, the same as negentropy toward arête. Against the intrinsic system trying to entropy ceaselessly, a person should put forth a great deal of effort to be self-renewal and self-creating with greater efforts staying in the state of negentropy. It lasts all one's life long. Even though an expert obtained some level of expertise and exercised most of his hidden talent, later on he can be faced with his no capabilities to deal with a problem if he was lax in learning and followed his own entropy. As soon as one abandons his efforts trying to achieve expertise to entropy, the expertise is lost its vitality. One should understand its state of process and aspire toward arête consistently throughout one's life.

Expertise Development shows the continuum between the organic and the social put in action. Motive and competence are closed to the organic because they contain personal characteristics more, and reason is closed to the social because the standard of judgment belongs to the given society mostly. Curiosity can ask, "Why?" and well as, "How?', while an expert is in practice. He often faces conflicting objective standards of excellence; the desire to do something well for its own sake can be impaired by competitive pressure, by frustration, or by obsession. That is able to be told in terms of conflict between the social and the organic. As one's expertise reaches higher phase, the expert will consider more about what the society expects from him and common good.

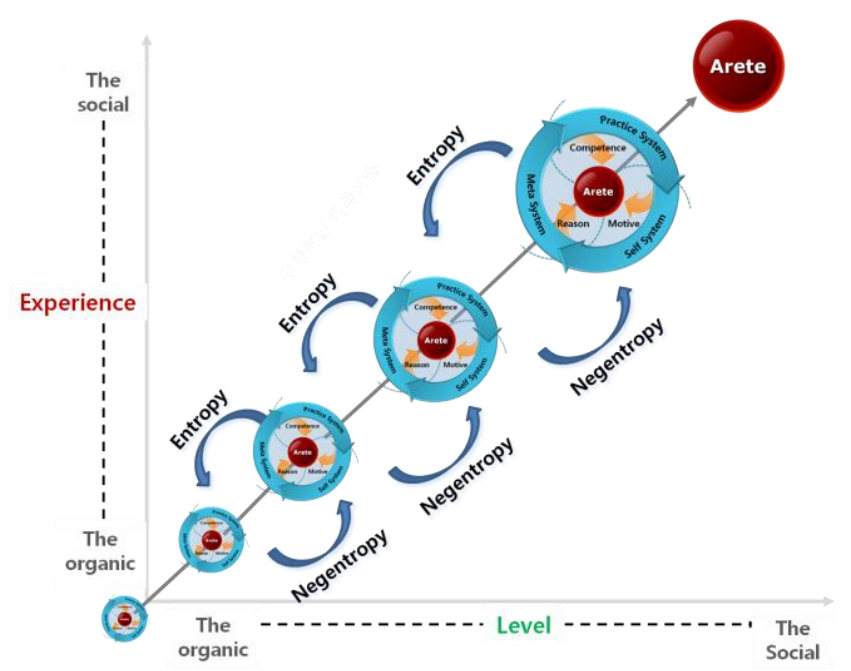

Fig. 4. Process of expertise development.

As shown in Fig. 4 above, the process of expertise development is persisting process toward arête and one who with 'mind as a whole' unified competence, motive, and reason is interacting among them and expanding the scope from the organic to the social. The expertise can be intensified to the superlative standard only with deliberate and systemic efforts based on understanding attributes of expertise. Though human experiences are the most significant foundation of expertise development, there is a certain limit to reach the superb level only with experiences. Therefore, it is necessary to put forth a multilateral effort into continuous developing expertise with intended systemic planning and concrete practice.

\section{REFERENCES}

[1] E. K. Bae, "Human resource development," Seoul: hakisisop, 2009.

[2] B. L. Benderly, "Everyday intuition," Psychology Today, pp. 34-40, 1989.

[3] R. W. Herling, "Expertise: The development of an operational definition for human resource development," in R. J. Torraco, Ed., Academy of Human Resource Development Proceedings, Baton Rouge, LA: AHRD, 1998, pp. 715-722.

[4] J. R. Hayes and D. Bajzek, "Understanding and reducing the knowledge effect: Implications for writers," Written Communication, vol. 25, no. 1, pp. 104-118, 2008.

[5] D. A. Schon, "The reflective practitioner: How professionals think in action," Basic Books, New York, 1983.

[6] A. De Groot, "Thought and choice in chess," Hague, Netherlands: Mouton, 1978

[7] H. L. Dreyfus and S. E. Dreyfus, Mind over machine : The power of human intuition and expertise in the era of the computer, New York: Free Press, pp. 16-51, 1986.

[8] K. A. Ericsson and A. C. Lehmann, "Expert and exceptional performance: Evidence on maximal adaptations on task constraints," Annual Review of Psychology, vol. 47, pp. 273-305, 1996.

[9] Feldman, "Beyond universals in cognitive development: 2nd," Westport, Connecticut: Ablex Publishing, 1994.

[10] H. A. Simon and W. G. Chase, "Skill in chess," American Scientist, 61, pp. 394-403, 1973.

[11] J. Tagg, "Learning outcomes and the development of expertise," On the Horizon, vol. 15, no. 2, pp.89-98, 2007

[12] C. Bereiter and M. Scardamalia, "Expert knowledge and how it comes about, surpassing ourselves: An inquiry into the nature and implications of expertise," La Salle, IL: Open Court, 1993.

[13] M. Bourbonniere, M. Mezey, E. L. Mitty, S. Burger, A. Bonner, and B Bowers, "Expanding the knowledge base of resident and facility outcomes of care delivered by advanced practice nurses in long-term care," Policy, Politics, \& Nursing Practice, vol. 10, no. 1, pp. 64-70, 2009.

[14] D. A. Kolb, "Experiential learning: Experience as the source of learning and development," Englewood Cliffs, NJ: Prentice Hall, 1984

[15] J. Lave and E. Wenger, Situated learning: Legitimate peripheral participation, New York: Cambridge University Press, 1991.

[16] V. J. Marsick and K. E. Watkins, Informal and incidental learning in the workplace, New York, NY: Routledge, 1990.

[17] H. S. Oh and J. A. Kim, "Critical Research Issues and Future Directions in Expertise Research," Korea Society for Learning and Performance, vol. 9, no.1, pp. 143-168, June 2007.

[18] B. S. Bloom and L. A. Sosniak, Developing talent in young people, New York, NY: Ballantine, 1985.

[19] Ericsson and Lehmann, "Expertise," in M. A. Runco and S. R. Pritzker," (Ed.), Encyclopedia of creativity, San Diego, CA: Academic 1999, vol. 1, pp. 695-707.

[20] E. F. Goldman, "The power of work experiences: Characteristics critical to developing expertise in strategic thinking," Human Resource Development Quarterly, vol. 19, no. 3, pp. 217-239, 2008.

[21] K. A. Ericsson, (Ed.), The road to excellence: The acquisition of expert performance in the arts and sciences, sports, and games, Mahweh, NJ: Erlbaum, 1996.

[22] Ericsson, "How the expert performance approach differs from traditional approaches to expertise in sport," in J. L. Starkes and K. A. Ericsson, (Ed.), Expert performance in sports: Advances in research on sport expertise, Champaign, IL: Human Kinetics, 2003, pp. 360-402. 
[23] R. S. Grenier, "The role of learning in the development of expertise in museumdocents," Adult Education Quarterly, vol. 59, no. 2, pp. $142-157,2009$

[24] R. A. Swanson and E. F. Holton III, The nature of human expertise: Foundations of human resource development, San Francisco, CA: Berrett-Koehler Publishers, 2001.

[25] P. A. Alexander, "The development of expertise: The journey from acclimation to proficiency," Educational Researcher, vol. 32, no. 8, pp. $10-14,2003$

[26] B. L. Benderly, "Everyday intuition," Psychology Today, pp. 34-40, 1989.

[27] S. Hardy, A. Titchen, K. Manley, and B. McCormack, "Re-defining nursing expertise in the united kingdom," Nursing Science Quarterly, vol. 19 , no. 3, pp. 260-264, 2006.

[28] L. Sharoff, "A qualitative study of how experienced certified holistic nurses learn to become competent practitioners," Journal of Holistic Nursing, vol. 24, no. 2, pp. 116-124, 2006.

[29] R. L. Jacobs, "Systems theory applied to HRD," in D. B. Gradous. (Ed.), Systems theory applied to human resource development. Alexandria, 1988 , pp. $27-60$.

[30] P. M. Senge, "The fifth discipline: The art and practice of the learning organization," Doubleday/Currency, New York, 1990.

[31] R. W. Herling, "Operational definitions of expertise and competence," Advances in Developing Human Resources, vol. 2, no.1, pp. 8-21, 2000.

[32] Y. J. Ko, "Competency as a Practical Concept," The Korean Journal of Philosophy of Education, vol. 45, pp. 1-26, June 2009.

[33] I. Kant, Critique of Judgment, J. H. Bernard, Trans., London: Macmillan, 1914

[34] R. S. Peters, The concept of motivation, Oxford, England: Humanities Press, 1958

[35] H. L. Dreyfus and S. E. Dreyfus, Mind over machine: The power of human intuition and expertise in the era of the computer, New York, NY: Free Press, pp. 16-51, 1986.

[36] V. Bertalanffy, "General System Theory," General Systems, Yearbook of the Society for General Systems Research, vol. 1, 1956.

[37] R. S. Brumbaugh and N. M. Lawrence, Philosophers of Education: Six Essays on the Foundations of Western Thought, Houghton Mifflin Company, 1963.
[38] J. W. Paideia, The Ideals of Greek Culture, G. Highet, Trans., Oxford University Press, 1976

[39] R. Sennett, The Craftsman, New Haven \& London: Yale University Press, 2008, part. 3.

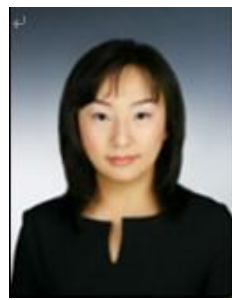

Young Koung Moon was born in Seoul, Korea. She received her master's degree from Fordham Graduate School of Education, New York, USA in Adult education and Human Resource Development in 2005. She is now a candidate of Ph.D.(ABD) in Educational Technology at Hanynag University in Korea. She teaches at Hanyang University and Hallym University in Korea for three years (2010-present). She worked as a business consultant for three years(2007-2009) in Mirae Management Development Institute in Korea.

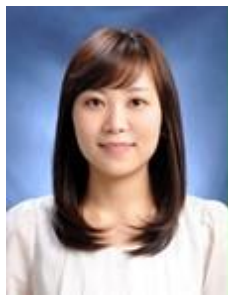

Eun Jung Kim was born in Seoul, Korea. She received her B. A. majored in Child Welfare and Studies from Sookmyung Women's University in 2011. She is now a student of Master's course in Department of Educational Technology in Hanyang University. She is currently working at Brain Korea 21 emerging e-learning research \& development team and her research interest is Human resource development and organizational learning.

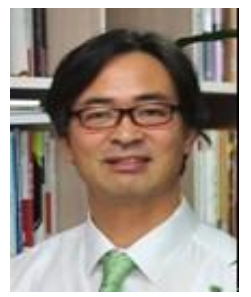

Yeong-Mahn You was born in Seoul, Korea. H received his M.A. from Hanyang University in Korea majored in Educational Technology in 1991, and Ph. D. from Florida State University majored in Instructional Systems in USA in 1993. He was working at Samsung Corp. at HRD Department for seven years(1993-1999). He is a professor at the Department of Educational echnology in Hanyang University in Korea for eleven years(2001-present).

His research interests are knowledge ecology, HRD as Happiness Revitalization Development etc. and he published over sixty books. 